\title{
A proposal for a new classification of complications in craniosynostosis surgery
}

\author{
Dmitri Shastin, MRCS, ${ }^{1}$ Sharron Peacock, RGN, RSCN, MSc, ${ }^{1}$ Velu Guruswamy, FRCA, FCARCSI, ${ }^{5}$ \\ Melpo Kapetanstrataki, MSc, ${ }^{6}$ David T. Bonthron, FRCP, FRCPath, ${ }^{6}$ \\ Maggie Bellew, PhD, CPsychol, ${ }^{3}$ Vernon Long, FRCOphth, ${ }^{4}$ Lachlan Carter, FRCS (OMFS), ${ }^{2}$ \\ lan Smith, FDSRCS, FRCS, FRCS (Plast), ${ }^{3}$ John Goodden, FRCS (NeuroSurg), ${ }^{1}$ \\ John Russell, FRCS, ${ }^{2}$ Mark Liddington, DPhil, FRCS, ${ }^{3}$ and Paul Chumas, MD, FRCS (SN) ${ }^{1}$
}

Departments of ${ }^{1}$ Neurosurgery, ${ }^{2}$ Maxillofacial Surgery, ${ }^{3}$ Plastic and Reconstructive Surgery, ${ }^{4}$ Ophthalmology, and ${ }^{5}$ Anaesthetics, Leeds General Infirmary; and ${ }^{6}$ School of Medicine, University of Leeds, United Kingdom

OBJECTIVE Complications have been used extensively to facilitate evaluation of craniosynostosis practice. However, description of complications tends to be nonstandardized, making comparison difficult. The authors propose a new pragmatic classification of complications that relies on prospective data collection, is geared to capture significant morbidity as well as any "near misses" in a systematic fashion, and can be used as a quality improvement tool.

METHODS Data on complications for all patients undergoing surgery for nonsyndromic craniosynostosis between 2010 and 2015 were collected from a prospective craniofacial audit database maintained at the authors' institution. Information on comorbidities, details of surgery, and follow-up was extracted from medical records, anesthetic and operation charts, and electronic databases. Complications were defined as any unexpected event that resulted or could have resulted in a temporary or permanent damage to the child.

RESULTS A total of 108 operations for the treatment of nonsyndromic craniosynostosis were performed in 103 patients during the 5-year study period. Complications were divided into 6 types: 0 ) perioperative occurrences; 1) inpatient complications; 2) outpatient complications not requiring readmission; 3) complications requiring readmission; 4) unexpected long-term deficit; and 5) mortality. These types were further subdivided according to the length of stay and time after discharge. The overall complication rate was found to be $35.9 \%$.

CONCLUSIONS The proportion of children with some sort of complication using the proposed definition was much higher than commonly reported, predominantly due to the inclusion of problems often dismissed as minor. The authors believe that these complications should be included in determining complication rates, as they will cause distress to families and may point to potential areas for improving a surgical service.

https://thejns.org/doi/abs/10.3171/2017.1.PEDS16343

KEY WORDS craniosynostosis; complications; morbidity; outcome; audit; craniofacial

$\mathrm{S}$ INCE the pioneering work by Paul Tessier and his colleagues, there has been continued development of novel surgical and anesthetic techniques aimed at improving the outcomes and safety of craniosynostosis surgery. Paradoxically, 40 years on there is still a paucity of established objective measures, leading to difficulty in evaluating these advancements. ${ }^{38}$ Analysis of perioperative morbidity and mortality offers an important tool for such evaluation, but it is not without limitations..$^{25}$ To begin with, there is no agreement as to what complications (including nonsurgical and/or minor surgical) should be counted, producing wide variation in published morbidity rates, ranging between $0 \%$ and $40 \%$. $^{1,6,12,15,16,21,23,24,26 \text {, }}$ 32,34-36,39 Quality indicators, such as blood loss, transfusion load, hospital stay, and reoperation rates, also suffer from a lack of standardization. Blood loss is estimated by the anesthetic team or calculated from clinical markers, but poor correlation between these 2 methods ${ }^{20,30}$ makes them unreliable. Perioperative transfusion is not always recorded $d^{15,42}$ or may only pertain to intraoperative transfusion. ${ }^{28}$ There is no agreement whether it should be expressed as a rate, ${ }^{20}$ volume, ${ }^{16}$ volume-to-body-weight ratio, ${ }^{9,28}$ and/or number

ABBREVIATIONS ACS = American College of Surgeons; FOAR = frontoorbital advancement and remodeling; ICP = intracranial pressure; LOS = length of stay; MACR = major calvarial reconstruction; MICR = minor calvarial reconstruction; NSQIP = National Surgical Quality Improvement Program; SD = standard deviation.

SUBMITTED June 12, 2016. ACCEPTED January 12, 2017.

INCLUDE WHEN CITING Published online March 31, 2017; DOI: 10.3171/2017.1.PEDS16343. 
of units given. ${ }^{35}$ Length of hospital stay may vary considerably depending on local policies. ${ }^{15,25}$ Reoperation rate is commonly used to describe repeat surgery for cosmetic reasons, ${ }^{32,35}$ yet occasionally procedures for complications such as infection or CSF leak are included..$^{18}$ Lastly, the overwhelming majority of published data are collected retrospectively, ${ }^{15,16,18,32,36,42}$ likely resulting in underreporting of significant occurrences. ${ }^{2,36}$

In the United Kingdom, the "Oxford classification," designed by Steven Wall in the late 1990s, is used to tabulate complications for the Craniofacial National Audit (personal communication). This classification system splits complications into 5 types, focusing on prolonged discharge, reoperation, long-term sequelae, or death (Table 1). Although this classification has the advantage of simplicity and captures most complications, neither intraoperative complications nor readmissions are captured; moreover, the classification is not time-specific, and it is open to different interpretations for recording complications. The purpose of this paper is to describe a new classification of complications in craniosynostosis surgery introducing objective, time-specific criteria that can be used for internal audit and external benchmarking, appraisal of new techniques, and counseling of patients and families.

\section{Methods}

Data on complications of surgery for nonsyndromic craniosynostosis performed between 2010 and 2015 were collected from a prospective craniofacial audit database that is maintained by a craniofacial nurse specialist (S.P.) at our institution. This was complemented by retrospective analysis of medical records, anesthetic and operation charts, and electronic databases to gather information on patients' comorbidities, details of surgery, and follow-up. Comorbidities were grouped on the basis of systems involved, using a modified classification from Tahiri et al..$^{36}$ Syndromic cases (i.e., those morphologically and/or genetically associated with a recognized craniosynostosis syndrome) were excluded.

Procedures were split into major and minor calvarial reconstructions (MACR and MICR, respectively) for sagittal synostosis, frontoorbital advancement and remodeling (FOAR) for metopic and coronal synostosis, and posterior release as a first stage for bicoronal synostosis where indicated. MACR included total calvarial reconstructions, anterior or posterior two-thirds, and modified pi procedures; Renier $\mathrm{H}$ corrections with added occipital bullet remodeling were also allocated to this group. MICR consisted of localized corrections of saddle deformity, spring-assisted surgery, and unmodified Renier H corrections. While spring removal was not regarded as a separate procedure for purposes of data analysis, any related complications and transfusions were reviewed. Secondary procedures were considered separately and included second-stage operations for bicoronal or multisuture synostoses (defined as operations planned before but carried out after the index procedure), or in 1 case reshaping for a patient who had previously undergone an operation elsewhere. Craniotomies for intracranial hypertension were merged into a stand-alone category, irrespective of suture
TABLE 1. Oxford classification of complications in craniosynostosis surgery

\begin{tabular}{cl}
\hline Type & Description \\
\hline 1 & No delay in discharge, reoperation, or long-term sequelae \\
\hline 2 & Delay in discharge but no further operation required \\
\hline 3 & Reoperation but no long-term sequelae \\
\hline 4 & $\begin{array}{c}\text { Unexpected long-term deficit or neurological impairment- } \\
\text { permanent disability }\end{array}$ \\
\hline 5 & Mortality \\
\hline Courtesy of Steven Wall.
\end{tabular}

involvement or whether they were done as a primary or secondary procedure. Intracranial hypertension was defined as intracranial pressure (ICP) $>15 \mathrm{~mm} \mathrm{Hg}$ on invasive monitoring ${ }^{10,19}$ and/or presence of papilledema on fundoscopy ${ }^{19}$ as diagnosed by a pediatric ophthalmologist (V.L.) in the absence of hydrocephalus. ${ }^{19}$

Standard anesthetic practice involved an inhalational agent, remifentanil infusion, and adjunctive analgesia, as well as clonidine where needed. Scalp nerve blocks were used in most cases to reduce intraoperative bleeding and decrease the need for systemic opioids. A continuous autotransfusion system (Fresenius C.A.T.S., Terumo) was used in selected cases. Postoperatively, patients were admitted to a pediatric high-dependency unit with regular analgesia and morphine infusion as required. Special attention was given to fluid therapy because of the risk of acidosis. Hemoglobin levels were checked from arterial samples at 1, 4, and 24 hours after surgery; in addition, blood samples were sent for formal tests on Day 1. Blood transfusion $(10-20 \mathrm{ml} / \mathrm{kg}$ ) was initiated when the hemoglobin level was demonstrated to have decreased below 70 $\mathrm{g} / \mathrm{L}$. No agents such as tranexamic acid or erythropoietin were used during the study period to minimize the need for transfusion.

Complications were defined as any unexpected event that resulted in or could have resulted in temporary or permanent damage to the child. Complications were divided into 6 types (0-5) with 2 to 4 subcategories in each (Table 2). Means and standard deviations (SDs) were calculated using postoperative length of stay (LOS) for procedures with no associated adverse events. These were applied to define Categories 1A and 1B. Prolonged LOS (more than 2 SDs above the mean) was then counted toward complications irrespective of its association with adverse events. Inadvertent injury to the meninges was not considered a complication if the injury was small (few millimeters), repaired intraoperatively, and did not result in postoperative sequelae. Pyrexia of unknown origin was included only when specific management was given (antibiotic therapy and/or readmission). Where criteria for more than 1 category were satisfied (e.g., excessive blood transfusion [Category $0 \mathrm{~A}$ ] associated with prolonged stay [Category $1 \mathrm{~B}]$ ), both were counted. Complications requiring readmission were split into nonsurgical (Categories $3 \mathrm{~A}$ and $3 \mathrm{~B}$ ) and surgical (Categories $3 \mathrm{C}$ and $3 \mathrm{D}$ ). Surgical complications were defined as those relating to the wound, cranium, meninges, brain, or CSF that had to be treated with surgery. It was deemed appropriate to 
TABLE 2. Leeds classification of complications in craniosynostosis surgery

\begin{aligned} & \hline \multicolumn{1}{c}{ Type } \multicolumn{1}{c}{ Description } \\ & \hline \multicolumn{1}{c}{ A } Perioperative occurrences \\ & \hline B Excessive blood transfusion (>60 ml/kg) \\ & \hline C Unplanned surgical intervention during index admission \\ & \hline 1 Inpatient complications \\ & \hline A w/ normal LOS (w/in 2 SD) \\ & \hline B w/ prolonged LOS (>2 SD) \\ & \hline C W/ exceptionally prolonged LOS $(>2$ wks) \\ & \hline 2 Outpatient complications not requiring readmission \\ & \hline A $\leq 30$ days since discharge \\ & \hline B $>30$ days since discharge \\ & \hline 3 Complications requiring readmission \\ & \hline A Nonsurgical, $\leq 30$ days since discharge \\ & \hline B Nonsurgical, $>30$ days since discharge \\ & \hline C Surgical, $\leq 30$ days since discharge \\ & \hline D Surgical, $>30$ days since discharge \\ & \hline 4 Unexpected long-term deficit \\ & \hline A Resolved by 6 mos \\ & \hline B Present at 6 mos \\ & \hline D Mortality \\ & \hline B Inpatient or $\leq 30$ days since discharge \\ & \hline\end{aligned}

LOS = length of stay; SD = standard deviation.

categorize them separately (Table 3) using established definitions $\mathrm{s}^{8,14,39}$ where available. Subgaleal hematoma and noninfectious wound problems were specifically defined for purposes of this study as they are more common in craniosynostosis surgery. ${ }^{36,42}$ Conservatively managed wound infections were defined using the same criteria as those treated surgically. ${ }^{8}$ Unexpected long-term deficit (Categories 4A and 4B), when neurological, was defined according to Drake et al..$^{14}$

The proposed classification was designed in a collaborative process between the senior (P.C.) and first (D.S.) authors, circulated among and approved by the members of the unit's craniofacial team, and critically appraised by the unit's statistician (M.K.). Initially, a generalized version was drafted, which was then adjusted on the basis of the existing cohort. It was further refined, drawing on complications reported in the literature, conference presentations, and personal communication with other units, the ultimate goal being the development of an objective and robust system that could be used to tabulate all potential and actual complications that arise in craniofacial surgery. Internal validity was assessed by dividing the cohort into 2 equal groups (based on whether the operation was performed before or after August 23, 2012) and comparing the distribution of complications in each.

Statistical analysis was conducted using IBM SPSS Statistics 23 (IBM Corp.) and Stata 14 (StataCorp LP). For normally distributed variables, a t-test was used to compare means between groups. The Mann-Whitney test was used for variables that were not normally distributed. A chi-square test or Fisher exact test was used for categorical data. The threshold for significance was set at $\mathrm{p}<0.05$; all tests were 2-sided where applicable.

\section{Results \\ Patient Cohort}

Over the 5-year period, 108 procedures were undertaken in 103 children with nonsyndromic craniosynostosis (Table 4). Overall, $74 \%$ of patients did not have any associated comorbidities, $15 \%$ had 1 system affected, and $11 \%$ had 2 systems affected (Table 5). The median duration of follow-up was 12 months.

\section{Surgery}

The patients' mean age at surgery was 16.4 months $(9.4$ months for patients with sagittal synostosis). Procedures, anesthetic and surgical times, blood transfusion, and LOS are shown in Table 6. Six patients underwent surgery for intracranial hypertension (4 primary and 2 secondary procedures). Secondary procedures for intracranial hypertension were performed in patients with multisuture craniosynostosis 4 and 6 years after the index surgery. The mean anesthetic time for all cases was 4 hours 45 minutes, and the mean surgical time was 2 hours 55 minutes. Blood transfusions were administered perioperatively for $75.9 \%$ of procedures and intraoperatively during $56.6 \%$. The average amount of blood transfused per procedure was 11.2 $\mathrm{ml} / \mathrm{g}$ intraoperatively (SD 13.0) and $5.1 \mathrm{ml} / \mathrm{kg}$ postoperatively (SD 7.9); meaningful volumes were obtained with cell salvage on 4 occasions, allowing the additional transfusion volumes of 5, 10, 10, and $20 \mathrm{ml} / \mathrm{kg}$. Four patients had hematological disorders. Of those, 3 patients with sagittal synostosis had hemophilia A, and 1 patient with unicoronal synostosis had factor VII deficiency. Three of these patients received perioperative blood transfusions: 2 had fresh-frozen plasma and 1 required platelets. Three of 5 patients treated with spring-assisted surgery had their springs removed without complications and did not require blood transfusion; another 2 had an additional craniofacial procedure at the same sitting (outside the study period). All 5 procedures were carried out electively. The mean LOS for the cohort was 4.1 days (SD 3.7; Table 7).

\section{Complications}

There were 51 complications in 37 (35.9\%) of the 103 patients after 37 (34.3\%) of the 108 operations, including 11 cases of prolonged LOS (displayed in Fig. 1). Patients with comorbidities affecting 2 systems had significantly more complications than patients in the rest of the group $(p=0.004$, Fisher exact test). There were 22 mild wound problems (16 noninfectious problems; 6 superficial wound infections), but no deep wound infections. There was 1 instance of excessive blood transfusion (involving a patient with hemophilia A). The only major morbidity was a case of quadriparesis in a patient with unexpected postoperative cervical cord ischemia (described elsewhere $\left.{ }^{33}\right)$. No patient died. General anesthesia was used in the management of 10 complications (twice for $1 \mathrm{com}-$ plication), 8 representing readmissions more than 30 days 
TABLE 3. Detailed description of surgical complications requiring readmission by type

\begin{tabular}{|c|c|c|}
\hline Type & Definition & Notes \\
\hline \multicolumn{3}{|l|}{ Postop infection } \\
\hline Wound infection & $\begin{array}{l}\text { "One of erythema, discharge of purulent material, or separation of wound edges to expose subcu- } \\
\text { taneous tissue, often with fever. Purulent collection in epidural, subdural, or intraparenchymal } \\
\text { (abscess) location. Classified according to CDC definitions as superficial, deep or organ space." }\end{array}$ & \multirow{2}{*}{$\begin{array}{l}\text { Adopted from Drake et } \\
\text { al. (Appendix 2: non- } \\
\text { shunt related postop- } \\
\text { erative infections).14 } \\
\text { Refer to CDC definitions } \\
\text { for wound infection } \\
\text { reporting. }{ }^{8}\end{array}$} \\
\hline Meningitis & $\begin{array}{l}\text { "One of fever, meningismus, altered level of consciousness, CSF leukocytosis, and presence of } \\
\text { an organism on Gram stain, or growth of an organism from aseptically obtained CSF sample. } \\
\text { Growth of skin commensals in broth only will not be considered a positive culture." }\end{array}$ & \\
\hline $\begin{array}{l}\text { Noninfectious wound } \\
\text { problems ("wound } \\
\text { nonhealing") }\end{array}$ & $\begin{array}{l}\text { Wound problems (leakage, dehiscence, scabbing, granulation) that do not meet the definition for } \\
\text { wound infection but require additional surgical management ("wound toilet") w/ or w/o resuturing } \\
\text { or refashioning (w/ or w/o general anesthesia). } \\
\text { Wound revision for cosmetic reasons should be included under "undesired appearance requiring } \\
\text { revision." }\end{array}$ & $\begin{array}{l}\text { Defined by Shastin et al. } \\
\text { (present article). }\end{array}$ \\
\hline \multicolumn{3}{|l|}{ Postop hemorrhage } \\
\hline Intraventricular & $\begin{array}{l}\text { "Significant blood clot within ventricular system that forms a cast and expands ventricle to some } \\
\text { degree." }\end{array}$ & \multirow{5}{*}{$\begin{array}{l}\text { Adopted from Drake et } \\
\text { al. (Appendix 2: new } \\
\text { neurological deficit, } \\
\text { hemorrhage, and/or } \\
\text { stroke). }{ }^{14} \\
\text { Definition of subga- } \\
\text { leal clot added by the } \\
\text { authors of present } \\
\text { article. }\end{array}$} \\
\hline Parenchymal & $\begin{array}{l}\text { "A significant blood clot that expands the surgical bed, has mass effect on the surrounding brain, } \\
\text { and/or possibly produces symptoms and signs of decreased level of consciousness, or unex- } \\
\text { pected neurological deficit." }\end{array}$ & \\
\hline Subdural & $\begin{array}{l}\text { "A significant subdural blood clot that has mass effect on the surrounding brain more than expect- } \\
\text { ed from the surgical procedure, and/or possibly produces symptoms and signs of decreased } \\
\text { level of consciousness, or unexpected neurological deficit." }\end{array}$ & \\
\hline Extradural & $\begin{array}{l}\text { "A significant extradural blood clot that has mass effect on the surrounding brain more than } \\
\text { expected from the surgical procedure, and/or possibly produces symptoms and signs of de- } \\
\text { creased level of consciousness, or unexpected neurological deficit." }\end{array}$ & \\
\hline Subgaleal & $\begin{array}{l}\text { A subgaleal blood clot that is easily visible clinically or radiologically, significantly distends sur- } \\
\text { rounding soft tissues, and is sufficiently symptomatic as to require removal. }\end{array}$ & \\
\hline \multicolumn{3}{|l|}{ CSF-related disorders } \\
\hline Postop CSF leak & $\begin{array}{l}\text { "Discharge of watery fluid consistent with CSF (normally clear or blood tinged) through surgical } \\
\text { incision, CSF drainage catheter egress site, or other surgical corridor." }\end{array}$ & \multirow{4}{*}{$\begin{array}{l}\text { Adopted from Drake et } \\
\text { al. (Appendix 2: other } \\
\text { CSF-related compli- } \\
\text { cations). }{ }^{14} \\
\text { Refer to the original } \\
\text { document for subclas- } \\
\text { sification of CSF leak } \\
\text { \& pseudomeningo- } \\
\text { cele. }\end{array}$} \\
\hline $\begin{array}{l}\text { Postop pseudo- } \\
\text { meningocele }\end{array}$ & $\begin{array}{l}\text { "Collection of CSF beneath intact skin at surgical incision site that is easily visible clinically or } \\
\text { radiologically, significantly distends surrounding soft tissues, and is under increased pressure } \\
\text { when palpated." }\end{array}$ & \\
\hline $\begin{array}{l}\text { Postop hydro- } \\
\text { cephalus }\end{array}$ & $\begin{array}{l}\text { "One symptom or sign of raised ICP, and } 1 \text { positive ancillary test } \\
\text { Symptoms: headache, nausea, vomiting, decreased level of consciousness, irritability, loss of } \\
\text { developmental milestones } \\
\text { Signs: papilledema, bulging fontanelle, depressed level of consciousness[,] sixth cranial nerve(s) } \\
\text { paresis, loss of upward gaze, new seizures (or increased seizure frequency), increasing head } \\
\text { circumference, CSF leak from incision or extraventricular drainage site, moderate to severe } \\
\text { pseudomeningocele } \\
\text { Ancillary tests: } \\
\text { (a) CT scan, ultrasound, or MRI scan showing enlarged ventricles compared with baseline or } \\
\text { failure to decrease in size compared with the preoperative study } \\
\text { (b) ICP monitoring showing persistent elevation of pressure with or without plateau waves OR } \\
\text { persistent requirement of external CSF drainage" }\end{array}$ & \\
\hline $\begin{array}{l}\text { Postop intracranial } \\
\text { CSF collection }\end{array}$ & $\begin{array}{l}\text { "Subdural fluid, interhemispheral, posterior fossa collections that are large and associated with } \\
\text { mass effect or symptoms and signs otherwise indicative of increased ICP and require treatment } \\
\text { (drainage, repeat operation, or prolongation of hospital stay)." }\end{array}$ & \\
\hline \multicolumn{3}{|l|}{ Cosmetic outcome } \\
\hline $\begin{array}{l}\text { Undesired appear- } \\
\text { ance requiring } \\
\text { revision } \\
\text { ("revision") }\end{array}$ & $\begin{array}{l}\text { Unsatisfactory cosmetic outcome of index procedure (e.g., hardware failure or growing skull frac- } \\
\text { ture) requiring operation not planned before the index procedure. } \\
\text { Lesser: soft-tissue or lesser bone-contouring revisions } \\
\text { Intermediate: major alternative osteotomies or bone grafting procedures } \\
\text { Greater: craniofacial procedures duplicating or exceeding in extent the index procedure }\end{array}$ & $\begin{array}{l}\text { Based on Whitaker et al. } \\
\quad \text { (Categories II-IV). }{ }^{39}\end{array}$ \\
\hline
\end{tabular}


after discharge; 3 of the 8 readmissions were for revision procedures -1 for a growing skull fracture, 1 for a palpable bony defect, and 1 because of a protruding plate and screws (Table 8).

\section{MACR Versus FOAR}

The 2 largest surgical groups (MACR and FOAR) were compared in a separate analysis. There was a difference in age at surgery ( $\mathrm{p}<0.001$, Mann-Whitney test) but not duration of follow-up ( $p=0.22$, Mann-Whitney test). There was no statistically significant difference between the 2 groups with respect to LOS ( $p=0.20$, Mann-Whitney test), number of complications ( $p=0.22$, Fisher exact test), or type of complications ( $\mathrm{p}=0.45$, chi-square test). Additionally, the combination of MACR and FOAR was tested against MICR for the number of complications and was found to be statistically different $(p=0.005$, Fisher exact test), with no complications in the MICR group.

\section{Internal Validity}

The distributions of complications in the first and second periods of the study (54 procedures each) were compared to test the classification for internal validity. There were 24 complications in the first half and 27 in the second, with no difference in distribution ( $\mathrm{p}=0.32$, chi-square test).

\section{Discussion}

Recently, national guidelines and standardized parameters of care for craniosynostosis have been produced in Europe $^{25,29}$ and the United States, ${ }^{27}$ respectively. Nevertheless, substantial variations in practice owing to local expertise and setup remain. ${ }^{3}$ With the increasing prevalence of craniosynostosis globally ${ }^{13,22}$ and some evidence suggesting subtle long-term neurocognitive sequelae in untreated single-suture synostosis, ${ }^{4,5}$ surgery is more frequently undertaken than previously. ${ }^{13}$ It is thus crucial to constantly audit and refine perioperative care provided to craniosynostosis patients.

Complications are an important vehicle for outcome analysis across surgical specialties. ${ }^{7,14}$ While a number of classifications have been proposed focusing mainly on severity of resulting disability, interventions involved in complication treatment, or quality of life measures, ${ }^{7}$ adverse events are still too frequently reported in a descriptive manner using authors' custom definitions. Lately, increasing focus on safety and costs has prompted development of standardized definitions in several areas of surgery. ${ }^{14}$ In particular, the Canadian Pediatric Neurosurgery Study Group has formulated definitions of complications occurring in pediatric neurosurgery drawing on published prospective studies, randomized trials, quality indicators used by organizations such as Centers for Disease Control and Prevention, or consensus between the members of the group. ${ }^{14} \mathrm{~A}$ different take on adverse events analysis comes from reimbursement policies used by institutions such as Centers for Medicare and Medicaid Services in the United States $^{37}$ or the National Health Service (NHS) England in the United Kingdom..$^{30}$ These institutions monitor emergency readmissions within 30 days of discharge to make financial decisions - an approach that is likely to be in-
TABLE 4. Cohort characteristics for 103 patients and 108 procedures

\begin{tabular}{|c|c|}
\hline Characteristic & Value \\
\hline \multicolumn{2}{|l|}{ Sex } \\
\hline Male & $70(68 \%)$ \\
\hline Female & $33(32 \%)$ \\
\hline \multicolumn{2}{|l|}{ Age at op, mos } \\
\hline Mean & 16.4 \\
\hline SD & 15.7 \\
\hline \multicolumn{2}{|l|}{ Follow-up, mos } \\
\hline Median & 12 \\
\hline IQR & $3-23$ \\
\hline \multicolumn{2}{|l|}{ Type of craniosynostosis } \\
\hline \multicolumn{2}{|l|}{ Sagittal } \\
\hline No. of pts & 46 \\
\hline Sex, M:F & $77 \%: 23 \%$ \\
\hline Age at op in mos, mean (SD) & $9.4(4.8)$ \\
\hline \multicolumn{2}{|l|}{ Metopic } \\
\hline No. of pts & 21 \\
\hline Sex, M:F & $86 \%: 14 \%$ \\
\hline Age at op in mos, mean (SD) & $23.0(18.3)$ \\
\hline \multicolumn{2}{|l|}{ Unicoronal } \\
\hline No. of pts & 14 \\
\hline Sex, M:F & $36 \%: 64 \%$ \\
\hline Age at op in mos, mean (SD) & $16.7(7.2)$ \\
\hline \multicolumn{2}{|l|}{ Bicoronal } \\
\hline No. of pts & 5 \\
\hline Sex, M:F & $20 \%: 80 \%$ \\
\hline Age at op in mos, mean (SD) & $13.7(7.1)$ \\
\hline Lambdoid, no. of pts & 0 \\
\hline \multicolumn{2}{|l|}{ Multisuture } \\
\hline No. of pts & 14 \\
\hline Sex, M:F & $68 \%: 32 \%$ \\
\hline Age at op in mos, mean (SD) & $28.6(27.2)$ \\
\hline
\end{tabular}

IQR = interquartile range; pts = patients.

creasingly used in the future. ${ }^{37}$ Additionally, data from the American College of Surgeons (ACS) National Surgical Quality Improvement Program (NSQIP) has been used to identify outliers using 30-day mortality. ${ }^{41}$ These time-related markers quantify quality and safety of services using general terms as opposed to breaking data into multiple isolated components. They give a different dimension and allow for comparison between different units and cohorts and can be used to detect not just suboptimal but also above average performance. We speculated that extending the logic behind these measures to classify all possible complications specific to craniosynostosis surgery could represent a useful way to highlight areas that quality improvement should focus on the most.

The classification detailed in our paper aims to capture significant surgical morbidity as well as any near misses with little dependence on subjective definitions. The primary division (Types $0-5$ ) views complications at differ- 
TABLE 5. Comorbidities by craniosynostosis type in 103 patients

\begin{tabular}{|c|c|c|c|c|c|}
\hline Comorbidity & Sagittal & Metopic & Unicoronal & Bicoronal & Multisuture \\
\hline CNS/PNS & $2(4.2 \%)$ & $1(4.6 \%)$ & & $1(20.0 \%)$ & \\
\hline Gastrointestinal & $2(4.2 \%)$ & & & & \\
\hline Craniofacial (cleft lip, etc.) & & $2(9.1 \%)$ & & & \\
\hline Cardiovascular & & $3(13.6 \%)$ & $2(14.3 \%)$ & & $1(7.1 \%)$ \\
\hline Extremities & $1(2.1 \%)$ & $3(13.6 \%)$ & $1(7.1 \%)$ & & $2(14.3 \%)$ \\
\hline Endocrine & & $1(4.6 \%)$ & & & \\
\hline Respiratory & $1(2.1 \%)$ & $1(4.6 \%)$ & & & $2(14.3 \%)$ \\
\hline Urogenital & & $1(4.6 \%)$ & $1(7.1 \%)$ & & $3(21.4 \%)$ \\
\hline Hematological & $3(6.3 \%)$ & & $1(7.1 \%)$ & & \\
\hline Connective tissue disorders & & $1(4.6 \%)$ & & & \\
\hline Other & $1(2.1 \%)$ & $1(4.6 \%)$ & & & $1(7.1 \%)$ \\
\hline Total $^{*}$ & $8(14.6 \%)$ & $9(40.1 \%)$ & $3(21.4 \%)$ & $1(20.0 \%)$ & $6(42.9 \%)$ \\
\hline
\end{tabular}

CNS = central nervous system; PNS = peripheral nervous system.

Comorbidity categories based on Tahiri et al. ${ }^{36}$ Values represent numbers of patients (\%).

* Total number (\%) of patients with comorbid conditions by craniosynostosis type.

ent stages in relation to the index procedure; while the type will not always represent complication severity, the goal is to stratify complications in a useful way that will facilitate constructive analysis. Subtypes (A-D) were introduced to give further detail on complications.

Data captured under Type 0 (perioperative occurrences) is designed to highlight any instances of exposure to the risk of harm, even if ultimately no harm had resulted. The ACS NSQIP Pediatric database recognizes transfusion of $\geq 25 \mathrm{ml} / \mathrm{kg}$ of packed red cells or whole blood within 72 hours of surgery as a significant bleeding occurrence. Nonetheless, as Chow et al. pointed out, ${ }^{9}$ no data exist to demonstrate the influence of transfusion over this threshold on safety or outcome. Instead, analyzing data from the NSQIP Pediatric database for over a thousand patients undergoing cranial vault remodeling and using multivariate regression models, their group has demonstrated transfusion in excess of $60 \mathrm{ml} / \mathrm{kg}$ to be independently predictive of overall complications, medical complications, and increased length of stay. One patient in our cohort had transfusion above this threshold $(95 \mathrm{ml} /$ $\mathrm{kg}$ ); this patient had hemophilia A and required significant volumes of packed blood and fresh-frozen plasma during the perioperative period despite a preoperative hematology workup.
For Type 1 (inpatient complications), the limits set between subtypes were arbitrary; however, when translated to our cohort, most simple nonsurgical events were captured under Category 1A, while the more involved ones (melena managed with esophagogastroduodenoscopy; pyrexia and urinary tract infection both requiring prolonged courses of antibiotics) were captured under Category 1B. Prolonged hospital stay was considered separately (Fig. 1, Category 1B, other) as it was deemed significant from the audit perspective. Similarly, any inpatient stay in excess of 2 weeks was felt to be reflective of a significant adverse event in the context of craniosynostosis surgery irrespective of possible variations in hospital stay between individual neurosurgical units. Our 1 child with a permanent postsurgical deficit was counted in this category as well because of a postoperative inpatient stay of 39 days.

For Types 2-5, subcategories were set to conform to the globally collected quality indices. Thirty-day unplanned readmission and death indicators are collected by Medicare in the United States (https://www.medicare.gov/hos pitalcompare/Data/30-day-measures.html); similar monitoring exists for the NHS in Great Britain (https://www. gov.uk/government/uploads/system/uploads/attachment_ data/file/509697/2016-17_National_Tariff_Payment_Sys tem.pdf). ${ }^{30}$ Thirty-day readmission is conventionally seen

TABLE 6. Age at surgery, anesthetic and surgical time, blood transfusion, and postoperative LOS by type of surgery

\begin{tabular}{|c|c|c|c|c|c|c|c|c|}
\hline \multirow[b]{2}{*}{ Procedure Type } & \multirow{2}{*}{$\begin{array}{l}\text { No. of } \\
\text { Pts }\end{array}$} & \multirow{2}{*}{$\begin{array}{l}\text { Age at Op } \\
\text { in Mos, SD }\end{array}$} & \multirow{2}{*}{$\begin{array}{l}\text { Anesthestic } \\
\text { Time in Hrs }\end{array}$} & \multirow{2}{*}{$\begin{array}{c}\text { Surgical } \\
\text { Time in Hrs }\end{array}$} & \multicolumn{3}{|c|}{ Blood Transfusion in $\mathrm{ml} / \mathrm{kg}$} & \multirow{2}{*}{$\begin{array}{c}\text { LOS in } \\
\text { Days }\end{array}$} \\
\hline & & & & & Intraop & Postop & Total & \\
\hline MACR (sagittal) & 42 & $9.6(4.0)$ & $4: 33$ & $2: 43$ & 16.6 & 5.1 & 21.7 & 4.6 \\
\hline MICR (sagittal) & 9 & $7.3(2.8)$ & 3:07 & $1: 25$ & 0.0 & 4.3 & 4.3 & 2.2 \\
\hline FOAR (metopic/coronal) & 41 & $17.6(8.6)$ & $5: 14$ & $3: 23$ & 9.8 & 4.4 & 14.3 & 4.1 \\
\hline Posterior release/remodeling & 4 & $17.0(18.7)$ & 5:01 & $3: 14$ & 5.0 & 14.0 & 19.0 & 3.5 \\
\hline Craniotomy for raised ICP & 6 & $56.2(32.3)$ & $4: 48$ & $2: 45$ & 4.2 & 0.0 & 4.2 & 3.2 \\
\hline Other secondary procedures & 6 & $28.7(25.5)$ & $5: 00$ & $3: 13$ & 11.6 & 8.5 & 20.1 & 4.0 \\
\hline Overall & 108 & $16.4(15.7)$ & $4: 45$ & $2: 55$ & 11.2 & 5.1 & 16.3 & 4.1 \\
\hline
\end{tabular}

Values are means unless otherwise indicated. 
TABLE 7. Length of postoperative stay for index procedures stratified by presence or absence of adverse events

\begin{tabular}{lccc}
\hline & & \multicolumn{2}{c}{ No. of Adverse Events } \\
\cline { 3 - 4 } Variable & Total & None & $\geq 1$ \\
\hline No. of procedures & 108 & 75 & 33 \\
\hline LOS & & & \\
\hline Mean & 4.1 & 3.5 & 5.3 \\
\hline SD & 3.7 & 1.1 & 6.3 \\
\hline
\end{tabular}

as an indicator of hospital performance ${ }^{11}$ that is less affected by external factors (other complicating illnesses, patients' behavior, care after discharge). On the other hand, it has been argued that 30-day readmission in neurosurgery should be viewed as a sign of prudent care as patients can deteriorate rapidly and in this group, early intervention can prevent serious morbidity. ${ }^{11}$

General anesthesia is often administered to children for minor procedures (e.g., wound management, including removal of crusted scabs and hair) when it would not be used for older children or adults; this carries a small risk of side effects and will frequently cause worry to parents. ${ }^{2}$ Of the 10 patients in our cohort who had complications involving the need for general anesthesia (all 10 being represented in the readmission group), 4 received general anesthesia for day case procedures and the 4 others received it for procedures requiring a single night's stay. The 3 unplanned revisions were all captured under Category 3D (surgical
TABLE 8. Surgical readmissions by type*

\begin{tabular}{ll}
\hline \multicolumn{1}{c}{ Type } & No. of Readmissions \\
\hline Infection & \\
\hline Superficial wound infection & 2 \\
\hline Deep wound infection & 0 \\
\hline Noninfectious wound problem & 5 \\
\hline Revision & \\
\hline Lesser† & 2 \\
\hline Intermediate & 1 \\
\hline
\end{tabular}

* As defined in Table 3.

$\dagger$ Protruding plate and screws $(n=1)$ and bony defect $(n=1)$.

‡ Growing skull fracture.

complications requiring readmission more than 30 days after discharge). As a result of the relatively high rate of superficial wound problems, we have changed our suture type for the galea (replacing Vicryl with Monocryl). An ongoing audit is under way, but our early impression is that we are experiencing fewer problems-although this remains to be confirmed.

It would be very easy to miss a lot of our complications in a retrospective audit, hence the importance of collecting data in a prospective fashion. Minor problems are not always considered worthy of analysis..12,17 In our cohort, $64.1 \%$ of patients had no complications and only very few had significant morbidity, but a much larger percentage (35.9\%) had some minor complications. While in the long

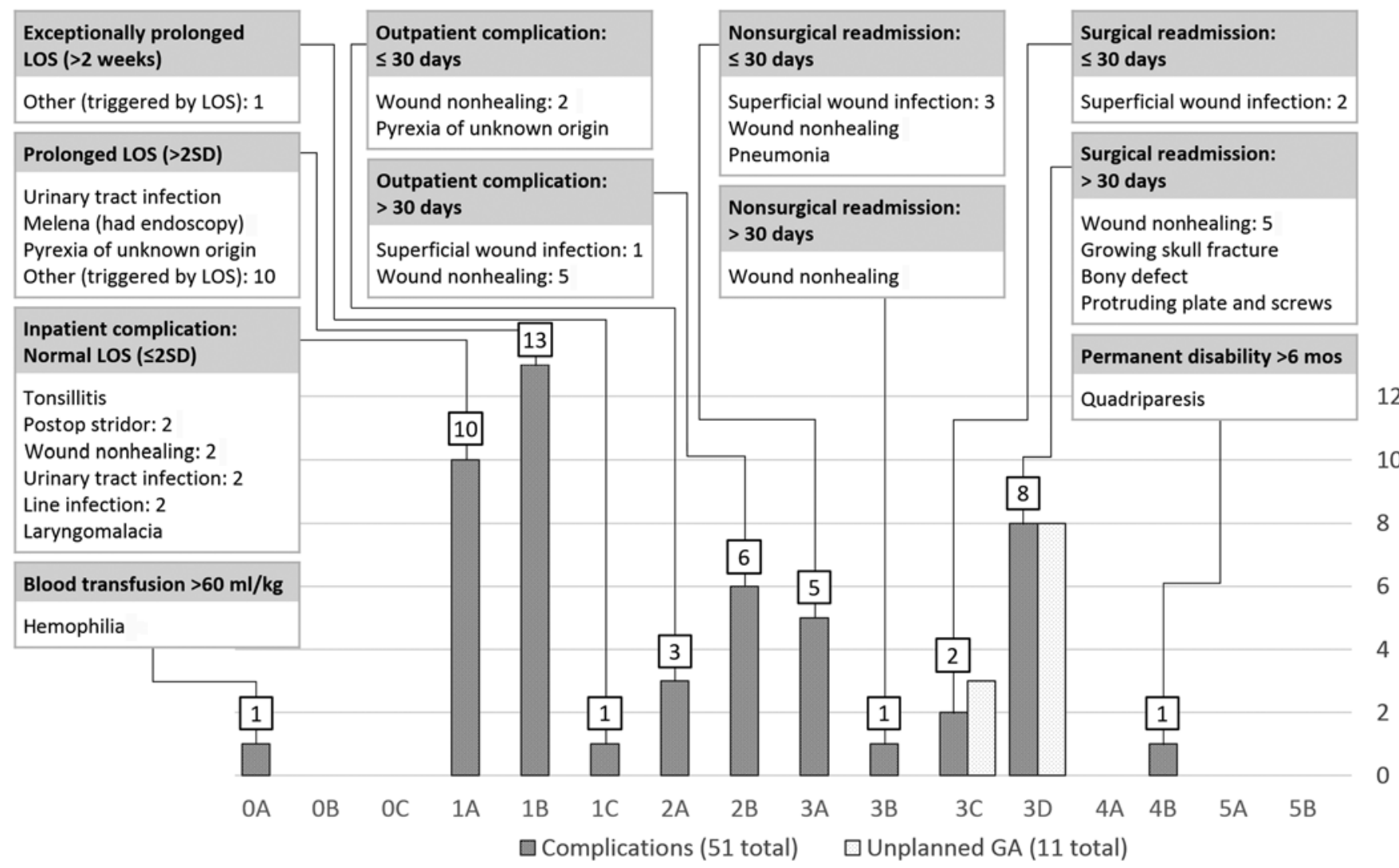

FIG. 1. Complications tabulated according to the proposed classification. GA = general anesthetic. 
run these may have no significant effect on the outcome, we believe they should be highlighted as they are likely to cause distress to families. ${ }^{2}$

The proposed classification system has several major strengths. Most groups are well defined, facilitating objectivity of data presentation and allowing capture of all possible complications. It is largely nonmodular; all data can be listed together, either in a table or a graph, facilitating comparison, although there is a mechanism in place for a detailed description of surgical complications requiring readmission. It contains a system of "triggers" that can be used to instigate internal investigation focusing on outlying categories. It is also specific to craniosynostosis surgery, although its expandability to other areas of pediatric neurosurgery deserves a separate evaluation. Finally, it is concordant with conventional hospital performance indices used by major institutions.

Some limitations should be mentioned. First, definition of reoperation may vary and may include interventions for cosmetic reasons (as described in the Whitaker classification of outcomes ${ }^{39}$ ) or any episode in which a patient is taken to the operating room and/or treated under general anesthesia. ${ }^{18}$ Because the main focus was on exposure to harm, a broader category tabulating all surgical complications (Category 3C/D) seemed more appropriate while still allowing for detailed description separately (Table 2). This may appear to be somewhat "diluted" by those "reoperations" made necessary by patients' young age (e.g., general anesthesia for wound management), nonetheless, we found such a division to be best suited to our purpose. Second, we have decided not to include accidental durotomies in our classification system, as complications from these should be picked up in any event (for the record, the accidental durotomy rate in our cohort was $14.8 \%$ ). While some publications $s^{15,18}$ include intraoperative durotomies under morbidity and these events could be viewed as exposing patients to risk of harm (e.g., growing skull fracture), currently no evidence is available to support that concern. Third, Category OB (significant anesthetic instability or complications) is the only category that, in our opinion, allows for subjective inclusion. To the best of our knowledge, there are no globally accepted classifications of anesthetic complications applicable to pediatric neurosurgery or craniosynostosis surgery. This may represent an area for future development. Fourth, some definitions proposed in Table 3 were made ad hoc, as a focused literature search yielded no suitable and well-established alternatives. We would welcome any suggestions on how these could be further improved. Last, the proposed classification is applied to a relatively small cohort of nonsyndromic patients, and its internal and external validity need to be examined further. Specifically, the mean age of operated patients in this cohort may appear older compared with previous Western publications. Children with craniosynostosis tend to present later in our region (mean age at referral overall and for sagittal synostosis: 8.4 and 4.8 months, respectively), consistent with some of the other British publications, ${ }^{40}$ so a smaller operation is often not available, thus warranting a higher rate of calvarial reconstruction. Additionally, we tend to operate later in cases of uni- and bicoronal craniosynostosis in an effort to decrease the need for revision surgery.

\section{Conclusions}

The authors propose a new classification of complications in craniosynostosis surgery that relies on prospective data collection and is geared to capture significant morbidity as well as any near misses in a systematic fashion. It can be used to enhance the quality improvement process, facilitate comparison of surgical techniques including in future prospective trials, and provide reliable information for patients and physicians alike. It represents a robust morbidity-recording tool that might be of use to other aspects of pediatric neurosurgery. As commented on by Drake et al. ${ }^{14}$ work of this type is fundamentally an iterative process and further modifications of the classification will be necessary and are welcomed. Lastly, this study shows that while serious morbidity after surgery for nonsyndromic craniosynostosis is low, the number of children developing some sort of complication is far higher (35.9\% of patients in the present series) when data are prospectively collected.

\section{References}

1. Allareddy V: Prevalence and impact of complications on hospitalization outcomes following surgical repair for craniosynostosis. J Oral Maxillofac Surg 72:2522-2530, 2014

2. Allibone JB, Harkness WJ, Hayward RD: Craniotomy-related complications in a paediatric neurosurgery unit-a prospective study. Br J Neurosurg 13:148-153, 1999

3. Alperovich M, Vyas RM, Staffenberg DA: Is craniosynostosis repair keeping up with the times? Results from the largest national survey on craniosynostosis. J Craniofac Surg 26:1909-1913, 2015

4. Bellew M, Chumas P: Long-term developmental follow-up in children with nonsyndromic craniosynostosis. J Neurosurg Pediatr 16:445-451, 2015

5. Bellew M, Liddington M, Chumas P, Russell J: Preoperative and postoperative developmental attainment in patients with sagittal synostosis: 5-year follow-up. J Neurosurg Pediatr 7:121-126, 2011

6. Breugem CC, van R Zeeman BJ: Retrospective study of nonsyndromic craniosynostosis treated over a 10 -year period. J Craniofac Surg 10:140-143, 1999

7. Brock S, Saleh C, Zekaj E, Servello D: How to compare clinical results of different neurosurgical centers? Is a classification of complications in neurosurgery necessary for this purpose? Surg Neurol Int 7 (Suppl 20):S565-S569, 2016

8. Centers for Disease Control: Surgical Site Infection (SSI) Event. (http://www.cdc.gov/nhsn/PDFs/ pscmanual/9pscssicurrent.pdf) [Accessed January 27, 2017]

9. Chow I, Purnell CA, Gosain AK: Assessing the impact of blood loss in cranial vault remodeling: a risk assessment model using the 2012 to 2013 Pediatric National Surgical Quality Improvement Program data sets. Plast Reconstr Surg 136:1249-1260, 2015

10. Christian EA, Imahiyerobo TA, Nallapa S, Urata M, McComb JG, Krieger MD: Intracranial hypertension after surgical correction for craniosynostosis: a systematic review. Neurosurg Focus 38(5):E6, 2015

11. Cusimano MD, Pshonyak I, Lee MY, Ilie G: Causes of 30day readmission after neurosurgery of the spine. J Neurosurg Spine 24:281-290, 2016

12. Czerwinski M, Hopper RA, Gruss J, Fearon JA: Major morbidity and mortality rates in craniofacial surgery: an analysis of 8101 major procedures. Plast Reconstr Surg 126:181-186, 2010

13. Di Rocco F, Arnaud E, Renier D: Evolution in the frequency of nonsyndromic craniosynostosis. J Neurosurg Pediatr 4:21-25, 2009 
14. Drake JM, Singhal A, Kulkarni AV, DeVeber G, Cochrane DD: Consensus definitions of complications for accurate recording and comparisons of surgical outcomes in pediatric neurosurgery. J Neurosurg Pediatr 10:89-95, 2012

15. Esparza J, Hinojosa J: Complications in the surgical treatment of craniosynostosis and craniofacial syndromes: apropos of 306 transcranial procedures. Childs Nerv Syst 24:1421-1430, 2008

16. Fearon JA, McLaughlin EB, Kolar JC: Sagittal craniosynostosis: surgical outcomes and long-term growth. Plast Reconstr Surg 117:532-541, 2006

17. Fearon JA, Yu J, Bartlett SP, Munro IR, Chir B, Whitaker L: Infections in craniofacial surgery: a combined report of 567 procedures from two centers. Plast Reconstr Surg 100:862 868,1997

18. Han RH, Nguyen DC, Bruck BS, Skolnick GB, Yarbrough CK, Naidoo SD, et al: Characterization of complications associated with open and endoscopic craniosynostosis surgery at a single institution. J Neurosurg Pediatr 17:361-370, 2016

19. Hayward R, Britto J, Dunaway D, Jeelani O: Connecting raised intracranial pressure and cognitive delay in craniosynostosis: many assumptions, little evidence. J Neurosurg Pediatr 18:242-250, 2016

20. Hentschel S, Steinbok P, Cochrane DD, Kestle J: Reduction of transfusion rates in the surgical correction of sagittal synostosis. J Neurosurg 97:503-509, 2002

21. Jeong JH, Song JY, Kwon GY, Baek SH, Kim JC, Choi TH, et al: The results and complications of cranial bone reconstruction in patients with craniosynostosis. J Craniofac Surg 24:1162-1167, 2013

22. Kweldam CF, van der Vlugt JJ, van der Meulen JJ: The incidence of craniosynostosis in The Netherlands, 1997-2007. J Plast Reconstr Aesthet Surg 64:583-588, 2011

23. Lee HQ, Hutson JM, Wray AC, Lo PA, Chong DK, Holmes $\mathrm{AD}$, et al: Analysis of morbidity and mortality in surgical management of craniosynostosis. J Craniofac Surg 23:1256-1261, 2012

24. Lin Y, Pan IW, Mayer RR, Lam S: Complications after craniosynostosis surgery: comparison of the 2012 Kids' Inpatient Database and Pediatric NSQIP Database. Neurosurg Focus 39(6):E11, 2015

25. Mathijssen IM: Guideline for care of patients with the diagnoses of craniosynostosis: working group on craniosynostosis. J Craniofac Surg 26:1735-1807, 2015

26. McCarthy JG, Glasberg SB, Cutting CB, Epstein FJ, Grayson $\mathrm{BH}$, Ruff $\mathrm{G}$, et al: Twenty-year experience with early surgery for craniosynostosis: I. Isolated craniofacial synostosis - results and unsolved problems. Plast Reconstr Surg 96:272283, 1995

27. McCarthy JG, Warren SM, Bernstein J, Burnett W, Cunningham ML, Edmond JC: Parameters of care for craniosynostosis. Cleft Palate Craniofac J 49 Suppl:1S-24S, 2012

28. Mutchnick IS, Maugans TA: Nonendoscopic, minimally invasive calvarial vault remodeling without postoperative helmeting for sagittal synostosis. J Neurosurg Pediatr 9:222-227, 2012

29. NHS England: 2013/14 NHS Standard Contract For Craniofacial Service (All Ages). (http://www.england. nhs.uk/wp-content/uploads/2013/06/e02-craniofacial.pdf) [Accessed January 27, 2017]

30. NHS England: 2016/17 National Tariff Payment System. (https://www.gov.uk/government/uploads/system/uploads/ attachment_data/file/509697/2016-17_National_Tariff_ Payment_System.pdf) [Accessed January 27, 2017]

31. Seruya M, Oh AK, Boyajian MJ, Myseros JS, Yaun AL, Keating RF: Unreliability of intraoperative estimated blood loss in extended sagittal synostectomies. J Neurosurg Pediatr 8:443-449, 2011

32. Seruya M, Oh AK, Boyajian MJ, Posnick JC, Myseros JS, Yaun AL, et al: Long-term outcomes of primary craniofacial reconstruction for craniosynostosis: a 12-year experience. Plast Reconstr Surg 127:2397-2406, 2011

33. Sheikh A, Warren D, Childs AM, Russell J, Liddington M, Guruswamy V, et al: Paediatric spinal cord infarction-a review of the literature and two case reports. Childs Nerv Syst [epub ahead of print], 2016

34. Shweikeh F, Foulad D, Nuño M, Drazin D, Adamo MA: Differences in surgical outcomes for patients with craniosynostosis in the US: impact of socioeconomic variables and race. J Neurosurg Pediatr 17:27-33, 2016

35. Sloan GM, Wells KC, Raffel C, McComb JG: Surgical treatment of craniosynostosis: outcome analysis of 250 consecutive patients. Pediatrics 100:E2, 1997

36. Tahiri Y, Paliga JT, Wes AM, Whitaker LA, Bartlett SP, Taylor JA: Perioperative complications associated with intracranial procedures in patients with nonsyndromic singlesuture craniosynostosis. J Craniofac Surg 26:118-123, 2015

37. Teufack SG, Campbell P, Jabbour P, Maltenfort M, Evans J, Ratliff JK: Potential financial impact of restriction in "never event" and periprocedural hospital-acquired condition reimbursement at a tertiary neurosurgical center: a single-institution prospective study. J Neurosurg 112:249-256, 2010

38. Warren SM, Proctor MR, Bartlett SP, Blount JP, Buchman SR, Burnett W, et al: Parameters of care for craniosynostosis: craniofacial and neurologic surgery perspectives. Plast Reconstr Surg 129:731-737, 2012

39. Whitaker LA, Bartlett SP, Schut L, Bruce D: Craniosynostosis: an analysis of the timing, treatment, and complications in 164 consecutive patients. Plast Reconstr Surg 80:195-212, 1987

40. White N, Warner RM, Noons P, McAlister EM, Solanki G, Nishikawa $\mathrm{H}$, et al: Changing referral patterns to a designated craniofacial centre over a four-year period. J Plast Reconstr Aesthet Surg 63:921-925, 2010

41. Wong JM, Bader AM, Laws ER, Popp AJ, Gawande AA: Patterns in neurosurgical adverse events and proposed strategies for reduction. Neurosurg Focus 33(5):E1, 2012

42. Zakhary GM, Montes DM, Woerner JE, Notarianni C, Ghali GE: Surgical correction of craniosynostosis. A review of 100 cases. J Craniomaxillofac Surg 42:1684-1691, 2014

\section{Disclosures}

The authors report no conflict of interest concerning the materials or methods used in this study or the findings specified in this paper.

\section{Author Contributions}

Conception and design: Chumas, Shastin, Guruswamy. Acquisition of data: Chumas, Shastin, Peacock, Guruswamy, Bonthron, Bellew, Long, Carter, Smith, Goodden, Russell, Liddington. Analysis and interpretation of data: Chumas, Shastin. Drafting the article: Chumas, Shastin. Critically revising the article: all authors. Approved the final version of the manuscript on behalf of all authors: Chumas. Statistical analysis: Kapetanstrataki. Study supervision: Chumas.

\section{Supplemental Information \\ Previous Presentations}

Portions of this work were presented at the 25th European Society for Paediatric Neurosurgery Congress, Paris, France, May 11, 2016, and the Biannual Conference of the European Society of Craniofacial Surgery, Birmingham, United Kingdom, September 23, 2016.

\section{Correspondence}

Paul Chumas, Department of Neurosurgery, G Fl., Jubilee Wing, Leeds General Infirmary, Great George St., Leeds LS1 3EX, United Kingdom. email: p.chumas@nhs.net. 